$\mathrm{p}<0,001$, sau điều trị 03 ngày là $92,4 \pm 47,9$ $(\mu \mathrm{mol} / \mathrm{l})$ với $\mathrm{p}<0,001$. Trước điều trị trung bình phân mức NH3 máu là 2,66 0,97 , sau điêu trị 01 ngày là $1,81 \pm 1,06$, sau điều trị 03 ngày là $1,09 \pm 1,06$ với với $p<0,001$. Kết quả của chúng tôi cũng tương tự nghiên cứu của tác giả YongHan Paik [7].

\section{KẾT LUÂN}

Qua nghiên cứu điều trị 32 bệnh nhân hội chứng não gan do xơ gan. Lactulose đường thụt hậu môn có hiệu quả cải thiện nồng độ $\mathrm{NH} 3$ trong máu và triệu chứng lâm sàng đối với bệnh nhân có hội chứng não gan.

\section{TÀl LIỆ THAM KHẢO}

1. Häussinger D, Kircheis G, Fischer R, Schliess F, vom Dahl S: Hepatic encephalopathy in chronic liver disease: a clinical manifestation of astrocyte swelling and low-grade cerebral edema? Journal of hepatology 2000, 32(6): 1035-1038.

2. Bhatia V, Singh R, Acharya SK: Predictive value of arterial ammonia for complications and outcome in acute liver failure. Gut 2006, 55(1):98-104.

3. Bohra A, Worland $T$, Hui $S$, Terbah $R$, Farrell A, Robertson $\mathbf{M}$ : Prognostic significance of hepatic encephalopathy in patients with cirrhosis treated with current standards of care. World journal of gastroenterology 2020, 26(18):2221-2231.

4. Said VJ, Garcia-Trujillo E: Beyond Lactulose: Treatment Options for Hepatic Encephalopathy. Gastroenterology nursing : the official journal of the Society of Gastroenterology Nurses and Associates 2019, 42(3):277-285.

5. Hadjihambi A, Arias $\mathbf{N}$, Sheikh $\mathbf{M}$, Jalan R: Hepatic encephalopathy: a critical current review. Hepatology international 2018, 12(Suppl 1):135-147.

6. Sharma BC, Sharma $P$, Lunia MK, Srivastava S, Goyal R, Sarin SK: A randomized, doubleblind, controlled trial comparing rifaximin plus lactulose with lactulose alone in treatment of overt hepatic encephalopathy. The American journal of gastroenterology 2013, 108(9):1458-1463.

7. Paik YH, Lee KS, Han KH, Song KH, Kim MH Moon BS, Ahn SH, Lee SJ, Park HJ, Lee DK et al: Comparison of rifaximin and lactulose for the treatment of hepatic encephalopathy: a prospective randomized study. Yonsei medical journal 2005, 46(3):399-407.

\title{
VAI TRÒ CỦA DEXAMETHASONE TRONG BộC Lộ CỬA SỔ TRÒN CẤY ĐIÊ̂N CỰC ỐC TAI ĐỐI VỚI TRỞ KHÁNG IFT VÀ ĐÁP ỨNG THẦN KINH ART
}

\section{TÓM TẮT}

Mục tiêu: Đánh giá vai trò của Dexamethasone (DEX) trong bộc lộ cửa sổ tròn cấy điện cực ốc tai đối với kết quả đo trở kháng IFT và đáp ứng thần kinh ART. Phương pháp nghiên cứu: nghiên cứu mô tả tiến cứu cócan thiệp được thực hiện trên 33 bệnh nhân cấy điện cực ốc tai từ tháng 8/2020 đến tháng 8/2021và được chia làm 3 nhóm: nhóm bơm DEX trong lúc bộc lộ cửa sổ tròn, nhóm nhúng điện cực vào DEX và nhóm không sử dụng DEX. Kểt quả nghiên cứu: trở kháng cao nhất đo được tại 1 kênh điện cực là $22,4(\mathrm{k} \Omega)$, thấp nhất là $1,21(\mathrm{k} \Omega)$. Giá trị trung bình tai tất cả các kênh là 4,22(k $\Omega)$. Trở kháng trung bình đo được tại các nhóm kênh điện cực đỉnh, giữa, đáy đều đat kết quả tốt $(<5 \mathrm{k} \Omega)$, trở kháng trung bình thấp nhất đo được tại nhóm nhúng $\mathrm{DEX}$ với giá trị là $3,97 \pm 0,88(\mathrm{k} \Omega)$, tiểp đến là nhóm bơm DEX với giá trị là $4,27 \pm 1,41(\mathrm{k} \Omega)$, cao nhất là nhóm không sứ dụng $D E X$ với kết quả là $4,48 \pm 1,28(\mathrm{k} \Omega)$, tuy nhiên sự khác biệt giữa các nhóm không có ý

*Trường Đại học y Hà Nội

Chịu trách nhiệm chính: Nguyễn Đức Minh

Email: nguyenducminhminhminh@gmail.com

Ngày nhận bài: 5.7.2021

Ngày phản biện khoa học: 31.8.2021

Ngày duyệt bài: 6.9.2021

\section{Nguyễn Đức Minh*, Cao Minh Thành*}

nghĩa thống kê với giá trị $p>0,05$. Kết quả đo đáp ứng thần kinh ART tỷ lệ đáp ứng tốt tại các nhóm điên cực đỉnh, giữa, đáy lần lượt là 72,$7 ; 81,8$ và $84,8 \%$. Kết quả đo đáp ứng thân kinh ART tai 3 nhóm bơm DEX, nhúng DEX và không sử dụng DEXsự khác biệt không có ý nghĩa thống kê với p> 0,05. Kết luâan: Vai trò của Desamethasone trong bộc lộ cửa sổ tròn cây điên cực ốc tai đối với kết quả đo trở kháng IFT và đáp ứng thần kinh ART không có sự khác biệt có ý nghĩa thống kê so với nhóm đối chứng.

Tư khóa: cấy điện cực ốc tai, dexamethasone, trở kháng, đáp ứng thân kinh

\section{SUMMARY}

THE ROLE OF DEXAMETHASONE IN

EXPOSING THE ROUND WINDOW IN COCHLEAR IMPLANT SURGERY ON

IMPEDANCE IFT AND NERVE RESPONSE ART

Objective: Evaluation of the role of Dexamethasone (DEX) in exposing the round window in cochlear implant surgery on impedance field telemetry (IFT) and auditory nerve response telemetry (ART). Methods: prospective intervention research on 33 patients having operated cochlear from 8/2020 to $8 / 2021$ and was divided into 3 groups: pump DEX during exposingthe round window, electrode dip in DEX and the group doesn't use DEX. Results: The resultsimpedance field telemetry for the highest 
impedance at one electrode channel was $22,4(\mathrm{k} \Omega)$, the lowest was $1,21(\mathrm{k} \Omega)$, the average value at all channels was $4,22(\mathrm{k} \Omega)$. The average impedance measured at the apical, middle, and basal electrode channels all achieved good results $(<5 \mathrm{k} \Omega)$, the lowest average impedance was measured at the dip DEX group with a value of $3.97 \pm 0.88(\mathrm{k} \Omega)$, followed by the pump DEX group with a value of $4.27 \pm 1.41(\mathrm{k} \Omega)$, the highest was the group without DEX with a result of $4.48 \pm 1.28(\mathrm{k} \Omega)$, however the difference between the groups was not statistically significant with $p>0,05$. The results of auditory nerve response telemetry (ART): the good response rate at the apical, middle, and basal electrode groups was 72,$7 ; 81,8$ and $84.8 \%$. The results of auditory nerve response telemetry (ART) at the groups: pump DEX, electrode dip DEX and no DEX, the difference was not statistically significant with $p>0,05$. Conclusion: the role of Dexamethasone (DEX) in exposing the round window in cochlear implant surgery on impedance field telemetry (IFT) and auditory nerve response telemetry (ART) was not statistically different from the control group.

Keywords: Cochlear implant, dexamethasone, impedance field telemetry, auditory nerve response telemetry

\section{I. ĐặT VẤN ĐỀ}

Phẫu thuật cẫy ốc tai điện tử là một phương pháp phẫu thuật nhằm phục hồi khả năng nghe nói của người bệnh khi bị nghe kém nặng, điếc mà dùng máy trợ thính kém hoặc khônghiệu quả. Việc đánh giá dữ liệu khách quan trong quá trinh phẩu thuật là một phần quan trong của quy trình cãy ốc tai điện tử trên toàn thể giới. Đánh giá các thông số khách quan giúp cho việc phân tích, đánh giá tính toàn vẹn của thiết bị, vị trí của điện cực trong ốc tai cũng như xác định phản ứng thần kinh thính giác, hố trợ xác định tiên lượng, góp phần vào việc lựa chọn lập trình bộ thiết bị ngoài. Các quy trình trong phấu thuật được sử dụng phổ biến nhất hiện nay là phép đơ trở kháng IFT (impedance field telemetry) và phép đo đáp ứng thần kinh ART (auditory nerve response telemetry). Dexamethasone (DEX) là một corticosteroid tổng hợp có tác dụng chống viểm và ức chế miê̂n dịch cao được sử dụng trong nhiều bệnh lý liên quan đến tai trong như bệnh Ménière, điếc đột ngột, bệnh lý tự miển tổn thương tai trong. Ánh hưởng của DEX tại chỗ trong cấy điện cực ốc tai làm giảm đáp ứng viêm, giảm sự hình thành mô sợi xơ hóa từ đó làm giảm trở kháng, tăng đáp ứng thần kinh thính giác đã được báo cáo trong một số nghiên cứu trong khi một số nghiên cứu khác lại không cho thãy hiệu quả. Chính vì vậy chúng tổi nghiên cứu đề tài này với mục tiêu: Đánh giá vai trò của Dexamethasone trong bộc lộ cứa số tròn cây điện cực ớc tai đôi với trở kháng IFT và đáp ứng thần kinh ART.

\section{II. ĐỐI TƯỢNG VÀ PHƯƠ'NG PHÁP NGHIÊN CỨU \\ 2.1.Đối tượng nghiên cứu}

2.1.1. Cỡ mâ̂u. Số lượng 33 bệnh nhân được chẩn đoán nghe kém nặng/điếc và được phẫu thuật cấy điện cực ốc tai.

\subsubsection{Thời gian và địa điểm nghiên cứu}

- Thời gian nghiên cứu từ tháng 8/2020 đến tháng $8 / 2021$

- Địa điểm nghiên cứu: Bệnh viên Đại học $Y$ Hà Nội và bệnh viện đa khoa Tâm Anh

\subsubsection{Tiêu chuẩn lứa chơn}

- Bệnh nhân $\geq 12$ tháng tuổi

- Đánh giá chức năng nghe trước phẫu thuật:

ABR, ASSR chẩn đoán nghe kém nặng/điếc

- Có phim CLVT, CHT xương thái dương

- Bệnh nhân được chia làm nhóm sử dụng DEX và nhóm không sử dụng DEX

- Bệnh nhân được đo trở kháng IFT và đáp ứng thần kinh ART sau đặt điện cực

- Gia đình đồng ý tham gia nghiên cứu

\subsubsection{Tiêu chuẩn loại trừ}

- Bệnh nhân không đủ các điều kiện trên

- Bệnh án không ghi đầy đủ các thông tin cần nghiên cứu

\subsection{Phương pháp nghiên cứu}

2.2.1.Thiết kế nghiên cứu: Mô tả tiến cứu có can thiệp

\subsubsection{Phương tiện nghiên cứu}

- Máy nội soi Tai Mũ̃i Họng

- Máy đo chức năng nghe

- Phim CLVT và CHT trước phẫu thuật

- Bộ dụng cụ phẫu thuật cẫy ốc tai điện tử

- Ốc tai điện tử hãng MED-EL và OTICON

- Phần mềm đo trở kháng IFT và đáp ứng thần kinh ART

\subsubsection{Vật liệu nghiên cứu. Dexamethasone}

2.2.4. Thông số nghiên cứu

- Một số đặc điểm chung của mẫu nghiên cứu: tuổi, giới, mức độ nghe kém trước phẫu thuật

- Đặc điểm phim CLVT, CHT trước phẫu thuật

- Yếu tố khó khăn trong phẫu thuật bộc lộ cửa sổ tròn

- Kết quả phẫu thuật đo trở kháng IFT và ART của 3 nhóm: bơm DEX trong bộc lộ cửa sổ tròn (nhóm I), nhúng điện cực DEX (nhóm II) và nhóm không sử dụng DEX (nhóm III) tại 3 nhóm kênh điện cực: đỉnh, giữa, đáy.

*Tiêu chí đánh giá kết quả đo đáp ứng thần kinh ART:

- Đáp ứng tốt: các kênh điện cực xác định được ngưỡng kích thích, các sóng có hình dạng 
điển hình.

- Đáp ứng kém: các kênh điện cực chưa xác định được ngưỡng kích thích, có dạng sóng nhưng không điển hình

- Không đáp ứng: không xác định được ngưỡng kích thích, không có dạng sóng ,đophản xạ cơ bàn đạp tại các kênh điện cực không đáp ứng

2.2.5. Xử lý và phân tích số liệu. Phần mềm SPSS 20

2.3. Đạo đức nghiên cứu. Đề tài nghiên cứu được thực hiện trên các bệnh nhân và cha me các bệnh nhi tự nguyện tham gia nghiên cứu. Các thông tin riêng tư của bệnh nhân được giữ kín và tuân thủ đạo đức nghiên cứu chung.

\section{KẾT QUẢ NGHIÊN CỨU}

\section{1. Đặc điểm chung}

- Giới: Tỷ lệ nam/ nữ = 1,2

- Tuổi: Độ tuổi nhỏ nhất là 1 tuổi, lớn nhất là 17 tuổi, phổ biến nhất là nhóm 2-5 tuổi chiếm tỷ lệ $60,0 \%$, tiếp đến là nhóm $\leq 2$ tuổi chiếm tỷ lệ $23,3 \%$, nhóm trẻ trên 5 tuổi chiếm tỷ lệ ít nhất là $16,7 \%$.

3.2. Đặc điểm lâm sàng, cận lâm sàng trước phấu thuật

3.2.1 Khám tai mũi họng. $100 \%$ bệnh nhân có kết quả khám nội soi tai mũi họng bình thường.
3.2.2 Đánh giá chức năng nghe. Kết quả OAE refer cả 2 tai chiếm tỷ lệ $100 \%$. Có 2 trường hợp trong tổng số 33 bệnh nhân nghe kém mức độ nặng chiếm tỷ lệ 6,06\%, 31 trường hợp điếc chiếm tỷ lệ 93,94\%.

3.2.3 Hinh ảnh CLVT và MRI xương thái dương trước phẫu thuật. Có 3 bệnh nhân dị dạng tai trong chiếm tỷ lệ $9,1 \%$, trong đó có 2 bệnh nhân bất sản dây thần kinh ốc tai 2 bên

3.3 Kết quả phẫu thuậtcây ĐCôT

3.3.1 Yêu tố khó khằn trong bộc lộ cửa sổ tròn

Bảng 3.1 Yêu tố khó khăn trong bộc lộ cửa sổ tròn

\begin{tabular}{|c|c|c|}
\hline $\begin{array}{c}\text { Yếu tố khó khăn trong bộc } \\
\text { lộ cửa sổ tròn }\end{array}$ & $\mathbf{n}$ & $\mathbf{\%}$ \\
\hline Öng tai ngoài ngả sau & 15 & 45,5 \\
\hline Ngách mặt đặc ngà & 10 & 30,3 \\
\hline Hẹp ngách mặt & 21 & 63,6 \\
\hline Tố chức che lấp cửa số tròn & 13 & 39,4 \\
\hline Vị trí cứa số tròn bất thường & 8 & 24,2 \\
\hline Hẹp cửa số tròn & 4 & 12,1 \\
\hline
\end{tabular}

Nhận xét: Trên một bệnh nhân có thể gặp đồng thời nhiều yếu tố khó khăn trong đó hẹp ngách mặt chiếm tỷ lệ cao nhất là $63,6 \%$, hẹp cửa sổ tròn chiếm tỷ lệ ít nhất là $12,1 \%$.

\subsubsection{Vai trò của DEX đôii với trở kháng IFT}

Bảng 3.2 Kêt qua đo trở kháng IFT

\begin{tabular}{|c|c|c|c|c|c|}
\hline IFT(k $\boldsymbol{\Omega})$ & Bơm DEX & Nhúng DEX & Không DEX & Tống & p \\
\hline Điện cực đỉnh & $4,79 \pm 1,60(\mathrm{k} \Omega)$ & $4,42 \pm 1,03(\mathrm{k} \Omega)$ & $4,95 \pm 1,40(\mathrm{k} \Omega)$ & $4,72 \pm 1,34(\mathrm{k} \Omega)$ & 0,650 \\
\hline Điện cực giữa & $4,14 \pm 0,96(\mathrm{k} \Omega)$ & $3,73 \pm 0,72(\mathrm{k} \Omega)$ & $4,40 \pm 0,15(\mathrm{k} \Omega)$ & $4,09 \pm 0,97(\mathrm{k} \Omega)$ & 0,272 \\
\hline Điện cực đáy & $3,87 \pm 1,27(\mathrm{k} \Omega)$ & $3,64 \pm 1,08(\mathrm{k} \Omega)$ & $3,89 \pm 1,54(\mathrm{k} \Omega)$ & $4,05 \pm 1,21(\mathrm{k} \Omega)$ & 0,767 \\
\hline Tồng & $4,27 \pm 1,41(\mathrm{k} \Omega)$ & $3,97 \pm 0,88(\mathrm{k} \Omega)$ & $4,48 \pm 1,28(\mathrm{k} \Omega)$ & $4,22 \pm 1,24(\mathrm{k} \Omega)$ & 0,563 \\
\hline
\end{tabular}

Nhận xét: Trờ kháng cao nhất đo được tại 1 kênh điện cực là $22,4 \mathrm{k} \Omega$, thấp nhất là $1,21 \mathrm{k} \Omega$. Giá trị trung bình tại tất cả các kênh là $4,22 \mathrm{k} \Omega$. Trở kháng trung bình đo được tại các nhóm điện cực đỉnh, giữa, đáy đều đạt kết quả tốt $(<5 \mathrm{k} \Omega)$, trờ kháng trung bình thấp nhất đo được tại nhóm nhúng $\mathrm{DEX}$ với giá trị là $3,97 \pm 0,88(\mathrm{k} \Omega$, cao nhất tại nhóm không sử dụng $\mathrm{DEX}$ với kết quả là 4,48 $\pm 1,28(\mathrm{k} \Omega)$, tuy nhiên sự khác biệt này không có ý nghĩa thống kê với giá trị $\mathrm{p}>0,05$.

\subsubsection{Vai trò của $D E X$ đôi với đáp ứng thân kinh $A R T$}

Bảng 3.3 Kết quả đo ART tại điện cực đỉnh

\begin{tabular}{|c|c|c|c|c|c|c|c|c|}
\hline \multirow{2}{*}{ ART Nhóm } & \multicolumn{2}{|c|}{ Bơm DEX } & \multicolumn{2}{c|}{ Nhúng DEX } & \multicolumn{2}{c|}{ Không DEX } & \multicolumn{2}{c|}{ Tống } \\
\cline { 2 - 9 } & $\mathbf{n}$ & $\mathbf{\%}$ & $\mathbf{n}$ & $\mathbf{\%}$ & $\mathbf{n}$ & $\mathbf{\%}$ & $\mathbf{n}$ & $\mathbf{\%}$ \\
\hline Đáp ứng tốt & 8 & 72,7 & 9 & 81,8 & 7 & 60,6 & 24 & 72,7 \\
\hline Đáp ứng kém & 3 & 27,3 & 1 & 9,1 & 3 & 27,3 & 7 & 21,3 \\
\hline Không đáp ứng & 0 & 0 & 1 & 9,1 & 1 & 9,1 & 2 & 6,0 \\
\hline \multicolumn{7}{|c|}{} \\
\hline
\end{tabular}

Bảng 3.4 Kêt quả đo ART tại điện cức giữa

\begin{tabular}{|c|c|c|c|c|c|c|c|c|}
\hline \multirow{2}{*}{ ART Nhóm } & \multicolumn{2}{c|}{ Bơm DEX } & \multicolumn{2}{c|}{ Nhúng DEX } & \multicolumn{2}{c|}{ Không DEX } & \multicolumn{2}{c|}{ Tống } \\
\cline { 2 - 8 } & $\mathbf{n}$ & $\mathbf{\%}$ & $\mathbf{n}$ & $\mathbf{\%}$ & $\mathbf{n}$ & $\mathbf{\%}$ & $\mathbf{n}$ & $\mathbf{\%}$ \\
\hline Dáp ứng tốt & 9 & 81,8 & 10 & 90,9 & 8 & 72,7 & 27 & 81,8 \\
\hline Dáp ứng kém & 2 & 18,2 & 1 & 9,1 & 3 & 27,3 & 6 & 18,2 \\
\hline Không đáp ứng & 0 & 0,0 & 0 & 0,0 & 0 & 0,0 & 0 & 0,0 \\
\hline \multicolumn{7}{|c|}{$\mathrm{P}=0,649$} \\
\hline
\end{tabular}


Bảng 3.5 Kêt quả đo ART tại điện cực đáy

\begin{tabular}{|c|c|c|c|c|c|c|c|c|}
\hline \multirow{2}{*}{ ART Nhóm } & \multicolumn{2}{c|}{ Bơm DEX } & \multicolumn{2}{c|}{ Nhúng DEX } & \multicolumn{2}{c|}{ Không DEX } & \multicolumn{2}{c|}{ Tống } \\
\cline { 2 - 8 } & $\mathbf{n}$ & $\mathbf{\%}$ & $\mathbf{n}$ & $\mathbf{\%}$ & $\mathbf{n}$ & $\mathbf{\%}$ & $\mathbf{n}$ & $\mathbf{\%}$ \\
\hline Đáp ứng tốt & 9 & 81,8 & 10 & 90,9 & 9 & 81,8 & 28 & 84,8 \\
\hline Đáp ứng kém & 2 & 18,2 & 1 & 9,1 & 1 & 9,1 & 4 & 12,1 \\
\hline Không đáp ứng & 0 & 0 & 0 & 0,0 & 1 & 9,1 & 1 & 3,1 \\
\hline \multicolumn{7}{|c|}{$\mathrm{P}=1,000$} \\
\hline
\end{tabular}

Nhận xét: Trên 33 bệnh nhân tỷ lệ đáp ứng tốt tại điện cực đỉnh, giữa, đáy lần lượt là 72,7 ; 81,8 và $84,8 \%$. Tỷ lệ đo ART đáp ứng tốt của từng nhóm bơm DEX, nhúng DEX và không sử dụng DEX tại các nhóm điện cực lần lượt nằm trong khoảng $(72,7-81,8 \%) ;(81,8-90,9 \%)$; $(60,6-81,8 \%)$, cao nhất tại nhóm nhúng DEX, thấp nhất ở nhóm không sử dụng DEX và sự khác biệt này không có ý nghĩa thống kê giữa các nhóm với giá trị $p>0,05$.

Có 2 bệnh nhân không có sóng đáp ứng tại điện cực đỉnh, 1 bệnh nhân không có sóng tại điện cực đáy. Không có bệnh nhân nào không có sóng đáp ứng trên 2 nhóm điện cực.

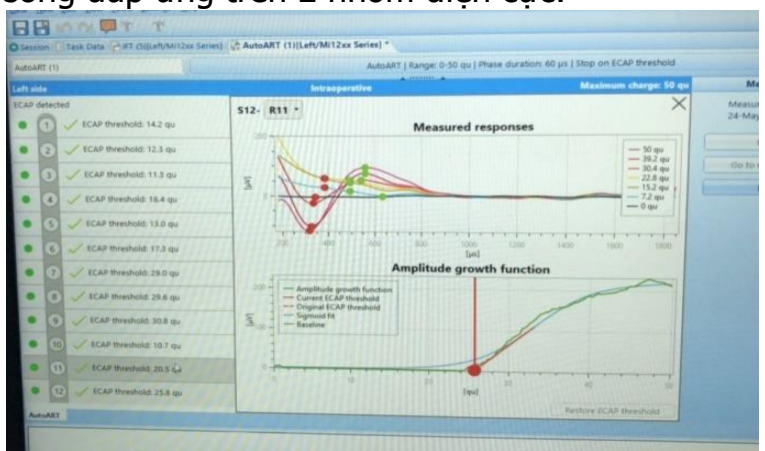

Hình 3.1 Kết quả đo ART đáp ứng tốt ở tất cả các nhóm kênh ở bệnh nhân Đỗ Thị Hoàng $D$, mã BA 2106003, ngày phẫu thuật 24/5/2021

\section{BÀN LUẬN}

4.1.Tuổi và giới. Trong nghiên cứu của chúng tôi tỷ lệ nam và nữ là tương đương nhau (nam/nữ $=1,1$ ), nhóm tuổi chiếm tỷ lệ cao nhất là nhóm 2-5 tuổi với tỷ lệ $60 \%$. Kết quả này tương đồng với các nghiên cứu khác của Lê Trần Quang Minh ${ }^{1}$ và Nguyển Thị Hải Lý ${ }^{2}$

\section{2. Đánh giá trước phẫu thuật}

*Đánh giá chức năng nghe

OAE: $100 \%$ refer cả 2 tai

Nghe kém mức độ nặng chiếm tỷ lệ 6,06\%, điếc chiếm tỷ lệ 93,94\%. Kết quả này tương đồng với kết quả của Cao Minh Thành ${ }^{3}$

*CLVT và MRI Xương thái dương. Dị dạng tai trong có 3 bệnh nhân chiếm tỷ lệ 9,1\%, trong đó có 2 bệnh nhân trên MRI thây hình ảnh dây thần kinh VIII 2 bên mảnh, có dây thần kinh tiền đình nhưng không thãy nhánh ốc tai 2 bên. Về mặt lý thuyết sự kích thích điện với điện cực trong ốc tai có thể không đến được thân não và vỏ não thính giác ở những bệnh nhân bất sản dây thần kinh ốc tai tuy nhiên đây không phải là chống chỉ định tuyệt đối của cây ĐCOT do những hạn chễ về độ phân giải MRI phát hiện dây thần kinh ốc tai trong những trường hợp nó quá mảnh và phản ứng của vỏ thính giác đối với âm thanh đã được xác định mặc dù dây thần kinh ốc tai khổng có trên hình ảnh MRI .

\subsection{Kết quả phẫu thuật}

4.3.1 Các yếu tố khó khăn trong bộc lô cửa sổ tròn. Trên cùng một bệnh nhân có thể gặp đồng thời nhiều yếu tố khó khăn trong bộc lộ cửa sổ tròn.

- Ống tai ngoài ngả sau chiếm tỷ lệ 45,5\% tỷ lệ này cao hơn nghiên cứu của Cao Minh Thành ${ }^{3}$, Nguyễn Thị Hải Lý2. Cũng theo Cao Minh Thành ống tai ngoài ngảa sau khó xác định cửa sổ tròn hơn trong lúc phẫu thuật ${ }^{3}$.

- Đặc điểm ngách mặt: trong nghiên cứu này ngách mặt đặc ngà chiếm tỷ lệ 30,3\%. Kết quả này tương tự tác giả Lê Trân Quang Minh ${ }^{1}$ với tỷ lệ 33,3\%. Hẹp ngách mặt chiếm tỷ lệ $63,6 \%$, tỷ lể này cao hớn kết quả nghiên cứu của Cao Minh Thành ${ }^{3}$.

- Đặc điểm cửa sổ tròn: Bất thường vị trí cửa sổ tròn chiếm tỷ lệ $24,2 \%$. Ở những bệnh nhân cửa sổ tròn không đúng vị trí đòi hỏi phẫu thuật viên phải khoan mỏng thành sau ống tai tạo trường quan sát và khoan mở rộng ngách mặt tìm cửa sổ tròn. $39,4 \%$ cửa sổ tròn có gờ xương hoặc tổ chức phần mềm che lấp 1 phần, kích thước cửa sổ tròn trung bình là $1,16 \pm 0,16 \mathrm{~mm}$

4.3.2 Kết quả đo từ xa trở kháng IFT. Trở kháng IFT phụ thuộc vào thiết kế của điên cực, cấu trúc mô, chất lỏng xung quanh và vị trí điện cực trong ốc tai. Trở kháng quá thấp $<0,5 \mathrm{k} \Omega$ gợi ý hiện tượng ngắnmạch giữa các điện cực. Trở kháng quá cao ( $>20-30 \mathrm{k} \Omega$ ) có thể là dấu hiệu của mạch hở như điện cực bị hỏng, điện cực nằm ngoài ốc tai hoặc có thể do sự xuất hiện của bọt khí trên bề mặt điện cực được hình thành trong quá trình cấy. Ngoài ra trở kháng có thể tăng do quá trình viêm nhiễm hình thành mô sợi phát triển xung quanh dãy điện cực. Trở kháng tăng ảnh hưởng xấu đến chức nắng của 
thiết bị cấy ốc tai, tăng tiêu thụ điện năng, giảm đáp ứng thần kinh thính giác.

Trong nghiên cứu của chúng tôi trên tổng số 484 kênh điện cực ở 33 bệnh nhân giá trị trở kháng đo cao nhất là $22,3 \mathrm{k} \Omega$, thấp nhất là $1,21 \mathrm{k} \Omega$. Chỉ có 2 kênh điện cực có giá trị trở kháng $>20 \mathrm{k} \Omega$, không có kềnh điện cực nào trở kháng $<0,5 \mathrm{k} \Omega$. Giá trị trung bình trở kháng của tất cả điện cực là $4,22 \pm 1,24 \mathrm{k} \Omega$, kết quả này tương đồng với kết quả nghiên cứu của Toner ${ }^{4} v a ̀$ à Wilk ${ }^{5}$. Giá trị trung bình trở kháng đo được tại các nhóm điện cựccao nhất tại nhóm điện cực đỉnh với giá trị là $4,72 \mathrm{k} \Omega$, điện cực giữa là $4,09 \mathrm{k} \Omega$, thấp nhất là nhóm điện cực đáy với kết quả $3,87 \mathrm{k} \Omega$, tuy nhiên sự khác biệt không có ý nghĩa thống kê với giá trị $p>0.05$. Kết quả này cũng tương đồng với kết quả của $\mathrm{Fu}^{-W \mathrm{~W}^{6}}$ và cộng sự khi kết quả đo trở kháng tại điện cực đỉnh là cao nhất, thấp nhất là tại điện cực đáy.

Giá trị trung bình trở khángtai các nhóm sử dụng DEX và nhóm đối chứng thì kết quả trở kháng thấp nhất tại nhóm điện cực nhúng DEX với giá trị là $3,97 \mathrm{k} \Omega$, cao nhất tại nhóm không sử dụng DEX với giá trị $4,48 \mathrm{k} \Omega$, tuy nhiên sự khác biêtt không có ý nghĩa thống kê với giá trị $p$ $>0,05$. Theo 1 nghiên cứu nghiên cứu của Wilk ${ }^{5}$ và cộng sự trên những bệnh nhân có sử dụng điện cực phóng thích DEX thì giá trị trở kháng ngay sau lắp điện cực không có sự khác biệt so với nhóm chứng, tuy nhiên ở những ngày thứ 7,28,90 sau phẫu thuật giá trị trở kháng điện cực đều tăng và nhóm sử dụng DEX có trở kháng tăng thấp hơn và sự khác biệt này có ý nghĩa thống kê so với nhóm không sử dụng DEX.

4.3.3 Kết quả đo đáp ứng thần kinh ART. Trên 33 bệnh nhân tỷ lệ đo ART đáp ứng tốt tại điện cực đỉnh là $72,8 \%$, điện cực giữa là $81,8 \%$ và điện cực đáy $84,8 \%$. Tỷ lệ này cao hơn so với nghiên cứu của Brill ${ }^{7}$ và cộng sự nghiên cứu trên 67 bệnh nhân với tỷ lệ đáp ứng tốt tại các nhóm điện cực lần lượt là 71,$1 ; 77,6$ và $56,7 \%$.

Có 2 bệnh nhân không có đáp ứng tại điện cực đỉnh, một ở nhóm nhúng điện cực DEX, một ở nhóm không sử dụng DEX. Có 1 bệnh nhân không có đáp ứng tại điện cực đáy ở nhóm không sử dụng DEX. Các bệnh nhân này đều có đáp ứng kém tại 1 trong các nhóm điện cực còn lại và trên hình ảnh cộng hưởng từ trước mổ các bềnh nhân này đều có dị dạng cấu trúc tai trong hoặc bất sản dây thần kinh ốc tai. Không có trường hợp nào không có sóng đáp ứng trên 2 nhóm điện cực. Việc vẫn có sóng đáp ứng mặc dù kém chứng tỏ trong các trường hợp này có thể vẫn có dây thần kinh ốc tai nhưng rất mảnh khiến cộng hưởng từ không thể xác định được trước mổ. Các bệnh nhân này kết quả cấy sẽ̃ khó đạt tương đương so với trẻ có cấu trúc bình thường.

Tại mỗi nhóm điện cực tỷ lệ đáp ứng tốt cao nhất đều ở nhóm điện cực nhúng DEX (lần lượt là 81,$8 ; 90,9 ; 90,9 \%)$, tiếp đến là nhóm bơm DEX, thấp nhất là ở nhóm không sử dụng DEX tuy nhiên sự khác biệt này không có ý nghĩa thống kê với giá trị $p>0,05$. Trong 1 nghiên cứu của Ramos và cộng sự tiến hành trên 3 nhóm bệnh nhân: nhóm 1 là nhóm đối chứng,nhóm 2 là nhóm được bơm $D E X$ trong lúc phẫu thuật bộc lộ cửa sổ tròn đăt điện cực,nhóm 3 là nhóm kết hợp bơm cả DEX và acid hyaluronic, nghiên cứu đã chỉ ra sử dụng dexamethasone kết hợp acid hyaluronic có sự khác biệt thống kê trong cải thiện đáp ứng thần kinh thính giác, sức nghe tốt hơn khi so với nhóm sử dụng DEX đơn độc và nhóm đối chứng, trong khi DEX đơn độc không tỏ ra lợi ích vượt trội so với nhóm đối chứng. Cũng trong 1 nghiên cứu khác của Hyun soo cho ${ }^{9}$ cũng cho thấy rằng sử dụng bơm $\mathrm{DEX}$ tại chỗ trong phẫu thuật thì có đáp ứng thần kinh, ngưỡng nghe tốt hởn so với nhóm chứng và sự khác biệt này có ý nghĩa thống kê. Trong nghiên cứu của chúng tôi tỷ lệ đáp ứng tốt của nhóm sử dụng DEX tốt hơn nhóm chứng, tuy nhiên sự khác biệt này không có ý nghĩa thống kê, có lẽ̃ do cỡ mẫu chưa đủ lớn, do vậy cần có nhiều nghiên cứu lớn hơn nữa để xác định lợi ích của desamethasone.

\section{KẾT LUÂN}

Đo từ xa trở kháng IFT và đáp ứng thân kinh ART cho phép ghi lại dữ liệu khách quan nhằm phân tích, đánh giá tính toàn vẹn của thiết bị, vị trí của điện cực trong ốc tai cũng như xác định phản ứng thần kinh thính giác, hỗ trợ xác định tiên lượng, góp phần vào việc lựa chọn lập trình bộ thiết bị ngoài.

Sử dụng DEX trong bộc lộ cửa sổ tròn và điện cực nhúng DEX có trở kháng IFT thấp hơn và đáp ứng thần kinh ART tốt hơn so với nhóm không sử dụng DEX, tuy nhiên sự khác biệt này không có ý nghĩa thống kê, cần có nhiều nghiên cứu lớn hơn nữa để xác định lợi ích của desemathasone.

\section{TÀI LIÊU THAM KHẢO}

1. Lê Trân Quang Minh. Nghiên cứu phẫu thuật cấy ốc tai đ̛̣ện tử đa kênh. Luận án tiến sĩ y học. 2015.

2. Nguyến Thị Hải Lý, Cao Minh Thành. Nghiên cứu khó khằn thường gặp trong đường vào cấy điện cức ốc tai. Luận văn Thạc sĩ y học. 2017.

3. Cao Minh Thành, Nguyê̂n Thị Trang. Một số bất thường về cấu trúc giải phẫu thường gặp trong 
phẫu thuật cấy ốc tai điện tử. Tạp chí Tai Mũi Họng Việt Nam.2020; 49-59.

4. Toner FM, Sanli $\mathbf{H}$, et al. Intraoperative Cochlear Implant Reinsertion Effects Evaluated by Electrode Impedance. Otology \& Neurotology. 2020;41(6): e695-e699.

5. Wilk $M$, Hessler $R$, Mugridge $K$, et al. Impedance Changes and Fibrous Tissue Growth after Cochlear Implantation Are Correlated and Can Be Reduced Using a Dexamethasone Eluting Electrode. Yamamoto M, ed. PLoS ONE. 2016; 11(2): e0147552.

6. Fu- Wei,Tao- Hsin Tung, et al. Evolution of impedance values in cochlear implant patients after early switch-on. PLoS One. 2021; 16(2): e0246545.

7. Brill S, Müller J, Hagen R, et al. Site of cochlear stimulation and its effect on electrically evoked compound action potentials using the MED-EL standard electrode array. BioMed Eng OnLine. 2009; 8(1):40.

8. Ramos BF, Tsuji RK, Bento RF, et al. Hearing preservation using topical dexamethasone alone and associated with hyaluronic acid in cochlear implantation. Acta Oto-Laryngologica. 2015; 135(5): 473-477.

\section{MộT Số ĐẶC ĐIỂM DİCH TỄ HỌC, CÁC YẾU Tố THờI TIẾT, VÉC TO' TRUYỀN BÊNH SỐT XUẤT HUYẾT DENGUE TẠI HUYỆN THANH TRİ, THẦNH PHỐ HÀ NộI, GIAI ĐOẠN 2016-2020}

\section{TÓM TẮT}

Mục tiêu: Nghiên cứu nhằm 2 mục tiêu, bao gồm mô tả một số đặc điểm dịch tễ của bênh Sốt xuất huyết Dengue và phân tích một số yếu tố thời tiết, véc tơ truyền bệnh của bệnh Sốt xuất huyết Dengue trên địa bàn huyện Thanh Trì, giai đoạn 2016-2020. Đối tượng và phương pháp nghiên cứu: Nghiên cứu sử dụng phương pháp mô tả cắt ngang có phân tích kết hợp hôi cứu toàn bô 4300 hồ sơ các ca bệnh SXHD được báo cáo và ghi nhận tại Trung tâm y tế huyện Thanh Trì, thành phố Hà Nối từ ngày 01/01/2016 đến ngày 31/12/2020. Kết quả: Hàng năm, số ca mắc SXHD tâp trung nhiều vào lứa tuổi từ 16 đến 45 , với nhóm tuổi từ 16-30 là 1389 ca và nhóm tuổi từ 31-45 là 1243 ca bệnh. Trong số 4438 ca bênh SXHD có sư tương đồng về giới tính, nam giới (2260, chiếm $50,9 \%)$; nữ giới (2178 ca, chiếm 49,1\%). Kết quả sử dụng kiểm định spearman cho thấy, mối liên quan giữa lượng mưa và số ca mắc SXHD của huyện Thanh Trì giai đoạn 2016 - 2020 là liên quan đồng biến ở mức trung bình với $r=0,1$, mối liên quan giữa nhiêtt độ và số ca mắc SXHD là liên quan đồng biến ở mức trung bình với $r=0,2$. Mối liên quan giữa lượng mưa và chỉ số BI aegypti SXHD là mối liên quan chặt chẽ với $r=0,6$. Mối liên quan giữa nhiệt độ và chỉ số $B I$ aegypti là mối liên quan chặt chẽ với $r=0,6$. Kết luận: Tại huyện Thanh Trì, giai đoạn 2016-2020, số ca bênh SXHD có xu hướng không đồng đều theo năm. Các trường hợp mắc SXHD cao nhất từ tháng 7 đến tháng 12 , thấp nhất từ tháng 1 đến tháng 4 , đỉnh

*Trung tâm Y tế dự phòng Thanh Tri **Đai hoc Y Hà Nội

Chịu trách nhiệm chính: Phạm Đăng Quân

Email: quanphamdang83@gmail.com

Ngày nhận bài: 2.7.2021

Ngày phản biên khoa hoc: 31.8.2021

Ngày duyệt bài: 6.9.2021

\section{Phạm Đăng Quân*, Chu Văn Thăng**, Trần Thu Phương*, Nguyễn Thị Ngọc Bích*}

dịch là vào tháng 8 . Mối liên quan giữa chỉ số BI aegypti và $\mathrm{BI}$ albopictus với số ca mắc SXHD là liên quan đồng biến ở mức trung bình. Mối liên quan giữa lượng mưa và nhiệt độ với chỉ số BI aegypti SXHD là các mối liên quan chặt chẽ

Tư khóa: Sốt xuất huyết Dengue; yếu tố thời tiết; vecto truyền bệnh; nhiệt độ; lượng mưa; độ ẩm.

\section{SUMMARY \\ EPIDEMIOLOGICAL CHARACTERISTICS, WEATHER FACTORS AND VECTORS OF DENGUE HEMORRHAGIC FEVER IN THANH} TRI DISTRICT, HANOI, 2016-2020

Purpose: The study aimed to describe epidemiological characteristics of Dengue Hemorrhagic Fever and to analyse weather factors and vectors of Dengue Hemorrhagic Fever in Thanh Tri District, 2016-2020. Materials and Methods: The study conducted cross-sectional descriptive method with retrospective analysis in total of 4,300 records of dengue cases reported and recorded at the Thanh Tri District Health Center, Hanoi from $1^{\text {st }}$ Jan, 2016 to $31^{\text {st }}$ Dec, 2020. Results: Every year, the number of dengue cases is highest in the age group from 16 to 45 , with 1389 cases in the 16-30 age group and 1243 cases in the 31-45 age group. Among 4438 dengue cases, male (2260, accounting for $50.9 \%$ ); women (2178 cases, accounting for $49.1 \%$ ). The results of using spearman test show that the association between precipitation and the number of dengue cases in Thanh Tri district in the period $2016-2020$ is positively related at an average level with $r=0.1$, the association between temperature and the number of dengue cases were positively related on average with $r=0.2$. The association between precipitation and BI aegypti dengue is significant with $r=0.6$. The association between temperature and aegypti BI is significant with $r=0.6$. Conclusion: In Thanh Tri district, 2016-2020, the number of dengue cases tends 